\title{
Autodescoberta e alteridade em Um quarto com vista e Maurice, de E. M. Forster
}

\author{
Self-discovery and alterity in A room with a view and \\ Maurice, by E. M. Forster
}

\section{Autodescubrimiento y alteridad en Una habitación com vistas y Maurice, de E. M. Forster} iD José Ailson Lemos de Souza
Universidade Estadual do Maranhão (UEMA), Balsas, Maranhão, Brasil.
Email: ailsonlsj@gmail.com

Resumo: Um Quarto com Vista (1908/2006) e Maurice (1913/2006), de E. M. Forster, são romances que tematizam a aprendizagem e a tomada de consciência sobre a problemática em torno das codificações de gênero e sexo na Inglaterra eduardiana. $O$ artigo objetiva analisar essas narrativas com destaque para a aprendizagem sobre si em Um Quarto com Vista (2006), e o processo de alteridade social como dispositivo de emancipação sexual em Maurice (2006), com base em discussões presentes em Mulvey (1989), Boes (2006), Kirsch (2015) e Butler (2015). É a partir da conscientização sobre os limites impostos pelo entrelaçamento de categorias como gênero e classe social que os personagens agem para inserir os próprios termos em suas trajetórias.

Palavras-chave: Alteridade. E. M. Forster. Gênero. Literatura inglesa.

Abstract: A room with a view (1908/2006) and Maurice (1913/2006), by $\mathrm{E}$. M. Forster, are novels that thematize processes of learning and coming to consciousness about the troubles concerning gender and sex codifications in Edwardian England. The aim of this work is to analyze these novels stressing the process of self-knowledge in A room with a view and the process of alterity as a sexual emancipatory means in Maurice, by 
considering some discussions presented in Mulvey (1989), Boes (2006), Kirsch (2015), and Butler (2015). The acknowledgment of the limits and the intertwining of gender and class are crucial for the characters action and their coming to terms with their own routes.

Keywords: Alterity. E. M. Forster. English Literature. Gender.

Resumen: Una habitación con vistas (1908/2006) y Maurice (1913/2006), de E. M. Forster, son novelas que se centran en el aprendizaje y la sensibilización sobre las cuestiones relacionadas con el género y las codificaciones sexuales en la Inglaterra eduardiana. Ese artículo tiene como objetivo analizar estas narrativas con énfasis en el aprendizaje sobre uno mismo en Una habitación con vistas (2006) y el proceso de alteridad social como dispositivo de emancipación sexual en Maurice (2006), considerando discusiones presentadas en Mulvey (1989), Boes (2006), Kirsch (2015) y Butler (2015). Es a partir de la conciencia de los límites que impone el entrelazamiento de categorías como género y clase social que los personajes actúan para insertar sus propios términos en sus trayectorias.

Palabras clave: Alteridad. E. M. Forster. Género. Literatura inglesa.

Submetido em 02 de outubro de 2020.

Aceito em 08 de dezembro de 2020.

Publicado em 24 de setembro de 2021. 
Autodescoberta e alteridade em um quarto com vista e Maurice, de E. M. Forster José Ailson Lemos de Souza

Um Quarto com Vista (1908/2006) e Maurice (1913/2006), de E. M. Forster, são romances de formação que pertencem ao período mais produtivo do autor contemporâneo de Virginia Woolf. Entre 1905 e 1910 foram publicados quatro romances de um conjunto de cinco obras publicadas em vida. Maurice, escrito entre 1913 e 1914, foi publicado postumamente em 1971. Um Quarto com Vista e Maurice enfatizam um processo gradativo do "conhecimento de si" dos protagonistas e a concomitante busca por emancipação. Diferente de outros romances do autor, as obras aqui analisadas têm um desfecho semelhante: um final feliz. A liberdade é uma conquista intermediada por processos de aprendizagem e alteridade de gênero e de classe social.

Lucy Honeychurch, em Um Quarto com Vista, visita Florença acompanhada de uma prima mais velha. Nessa viagem, conhece George, um turista compatriota cuja beleza física é por vezes sobreposta a formas masculinas com as quais Lucy se depara em capelas, afrescos e praças florentinas. George pertence a uma classe social mais baixa e a atração entre os dois é socialmente rechaçada. De volta à Inglaterra, Lucy compromete-se com Cecil Vyse, seu par social, mas cuja arrogância e falta de atrativos criam um impasse aparentemente supérfluo e cômico. No entanto, a comédia social construída em torno do despertar sexual de uma jovem inglesa no início do século XX revela-se uma análise penetrante sobre diferenças: classes sociais, perspectivas culturais, valores e códigos de comportamento.

Judith Herz (2007, p. 138) afirma que a crença na aparente simplicidade de Um Quarto com Vista, considerado uma leve "comédia de costumes", embaça questões complexas e imprevisíveis. Dentre essas questões, a autora sugere atenção sobre: a função do sexo e dos gêneros na narrativa; e a relação entre desejo e narração. Vale salientar que Maurice, considerado datado pelo tratamento dado à questão da homossexualidade, ao ser publicado postumamente (BOOTH, 2007), também teve sua "simplicidade" apontada por uma crítica pouco interessada em pensar sobre os problemas que a sexualidade ou a contestação de se abordar na ficção apenas 
Autodescoberta e alteridade em um quarto com vista e Maurice, de E. M. Forster José Ailson Lemos de Souza

uma de suas variantes trazem para o gênero literário quando pensamos e questionamos os termos impostos por aquilo que Judith Butler (2017) define como matriz heterossexual de poder.

O despertar sexual do protagonista, em Maurice, é também um despertar sobre os limites de seu lugar social: o status privilegiado resvala em garantir a liberdade antes irrestrita, quando a atração sexual pelo mesmo sexo torna-se cada vez mais latente, num período em que a homossexualidade era ilegal na Inglaterra. Em Cambridge, Maurice apaixona-se por Clive Durham. Através dele, abandona o conformismo em relação a dogmas sociais e religiosos. Com Alec Scudder, empregado de Clive, Maurice vive uma experiência profunda e transformadora que o leva a desertar do convívio social para viver com o amante. Apesar do intervalo temporal entre escrita e publicação de mais de meio século, o romance póstumo de Forster firma-se como importante realização ao desafiar, romper e ampliar paradigmas da tradição literária ocidental sobre a temática da homossexualidade.

Tobias Boes (2006) observa que, apesar de ser objeto de divergências críticas, o romance de formação tem como parte de suas características veicular mudanças, representar tomadas de consciência sobre si diante de valores sociais e culturais como forças de oposição ou opressão. Além do mais, esse gênero literário também tende a conectar o desenvolvimento pessoal e histórico a partir de narrativas de amadurecimento individual (BOES, 2006). No caso de Um Quarto com Vista (1908), a discussão sobre a liberdade sexual feminina antecipa-se ao debate cultural mais amplo sobre 0 tema, que se acentua nas décadas seguintes ao pós-guerra, com a crescente inserção de mulheres no mercado de trabalho. Em Maurice (1913), a realização individual do protagonista é alcançada a partir do abandono do convívio social, devido ao contexto legal na Inglaterra. A trajetória da obra confunde-se com as mudanças históricas, uma vez que é publicada em 1970, pouco tempo depois da descriminalização da homossexualidade no país, em 1967.

David Medalie (2002) observa que Forster deve ser lido no escopo de elaboração da literatura moderna inglesa, momento em 
Autodescoberta e alteridade em um quarto com vista e Maurice, de E. M. Forster José Ailson Lemos de Souza

que autores passam a fundir elementos divergentes e conflitantes da experiência que, cada vez mais, parecia insuficiente diante das rápidas mudanças nas condições de vida moderna. Medalie (2002) identifica na obra do romancista o emprego cada vez mais acentuado de ideias e técnicas simbolistas, apresentando uma narrativa mais afeita a significados implícitos, transições de difícil conexão, recuos em referenciar o mundo "real" - ou apreendê-lo por linhas obscuras e ambíguas, consequentemente, cada vez mais distanciando-se das técnicas realistas.

Nos romances em foco, a reflexão sobre classe e gênero surge a partir de imagens de grande carga simbólica, que examina a continuidade entre representação e experiência. Tal reflexão alinha-se a demandas para renovar, abrir espaços de diversidade e problematizar identidades como categorias não fixas, em constante processo de vir a ser.

A seguir, apresentamos uma leitura dessas narrativas, com destaque para o processo de aprendizagem sobre si da protagonista de Um Quarto com Vista (2006), e para o processo de alteridade social como dispositivo de emancipação sexual em Maurice (2006).

\section{Autodescoberta e as insuficiências de gênero em Um Quarto com Vista}

Um Quarto com Vista (2006) narra a transição da protagonista, Lucy Honeychurch, da infância para a vida adulta, momento marcado por uma viagem à Itália. Ela e Charlotte, a prima mais velha que a acompanha, conhecem os Emersons, pai e filho, uma dupla excêntrica que é esnobada pelo grupo de compatriotas que também visitam Florença, principalmente devido à classe social mais baixa. A excentricidade é um ponto em comum entre os diversos tipos com que Lucy e Charlotte têm contato durante a viagem: o reverendo Beebe, a escritora de folhetins Eleanor Lavish, as irmãs 
Autodescoberta e alteridade em um quarto com vista e Maurice, de E. M. Forster José Ailson Lemos de Souza

Allan (ainda mais velhas que Charlotte e Eleanor, todas mulheres maduras e solteiras).

Quando retorna para a Inglaterra, Lucy compromete-se com Cecil Vyse, um homem sem atrativos físicos, mas de posição social elevada. O jovem George Emerson permanece como objeto de desejo de Lucy ao longo da narrativa. Esse impasse entre classe social e desejo sexual será a base para um exame sobre diversos códigos de comportamento, sexo e gênero que então orientavam a sociedade inglesa, e que, segundo Kirsch (2015), Forster reveste como uma escolha entre danação (quando prevalecem as convenções) e salvação (quando prepondera a lei do desejo).

No interior da narrativa, George e Cecil são comparados a dois períodos históricos: a Renascença (George) e a Idade Média (Cecil). George tem sua beleza diversas vezes comparada às "pinturas de Michelangelo" (FORSTER, 2006a, p. 49, p. 181), enquanto que Cecil é descrito como um "homem medieval" e comparado a uma "estátua gótica" (FORSTER, 2006a, p. 127). Entre metáforas que acionam períodos distintos e formas masculinas, a liberdade sexual de Lucy será uma conquista intermediada por processos de alteridade de gênero e de classe social.

Uma das passagens mais importantes do romance, o assassinato na Piazza della Signoria, presenciado por Lucy e George, propicia uma interessante reflexão sobre gênero e representação no contexto de mudanças de paradigmas na modernidade, que reformularam aspectos conceituais das artes muito em decorrência da tecnologia e que oportunizou transformar os discursos que codificam a diferença sexual na representação.

Depois de receber elogios por executar uma peça de Beethoven ao piano na hospedaria, e conversar brevemente com a senhora Alan e Beebe, Lucy decide caminhar sozinha pela cidade. No percurso, pondera sobre os impasses para alcançar algo maior do que a convivência com seus pares sugere estar a seu alcance. Essa realização parece, num primeiro momento, ser algo simples, como um passeio de bonde. A reflexão é desperta a partir da orientação 
Autodescoberta e alteridade em um quarto com vista e Maurice, de E. M. Forster José Ailson Lemos de Souza

do reverendo Beebe para que ela caminhasse, pois tomar o bonde sozinha seria desaconselhável, pareceria algo "pouco feminino". A partir desta situação banal, Lucy envereda por um questionamento sobre o feminino: "Por que a maioria das coisas grandiosas era pouco feminina?" (FORSTER, 2006a, p. 67). Nessa ocasião, Lucy relembra a opinião de Charlotte. Segundo a prima, o papel da muIher seria inspirar os homens a atingir grandes feitos, sendo esse papel não o endosso de que fossem inferiores, mas uma questão de adequação aos costumes. Para Charlotte, com tato, boa reputação e consciência de que suas ações se dão de forma indireta, uma mulher poderia chegar longe. Charlotte talvez expresse um dos pontos de vista mais desacreditados por Lucy, tendo em conta as divergências entre elas e a carapaça servil expressa pela prima para obter vantagens.

Em seguida, surge uma justaposição entre a perspectiva de Lucy diante de uma representação feminina e os anseios sobre si mesma:

Há muito de imortal nessa dama de corte medievo. [...] Outrora, reinara em muitos castelos vitorianos e fora rainha de muitas canções vitorianas. É agradável protegê-la no intervalo dos negócios, é agradável elogiá-la quando ela prepara nosso jantar a contento. Mas infelizmente a criatura se degenera. Em seu coração, também brotam estranhos desejos. Ela também se enamora dos ventos fortes, dos vastos panoramas e das expansões verdes do mar. [...] Os homens, ao declararem que ela lhes inspira a lutar, movem-se alegremente sobre a superfície, indo aos mais deleitosos encontros com outros homens, felizes, não porque são másculos, mas porque estão vivos. Mas, antes que o espetáculo se disperse, ela anseia por abandonar o título de Mulher Eterna, e dirigir-se igualmente para lá, na condição de seu eu transitório (FORSTER, 2006a, p. 68).

O trecho põe em movimento significados em torno da representação, interpondo, como acontece em diversos pontos da nar- 
Autodescoberta e alteridade em um quarto com vista e Maurice, de E. M. Forster José Ailson Lemos de Souza

rativa, períodos históricos que ilustram a trajetória de opressão e exploração da mulher (Idade Média, Era Vitoriana). Um imaginário que sugere heroísmo romântico (ventos fortes, vastos panoramas, expansões verdes do mar), o aparentemente elogioso enquadramento da mulher na esfera da arte (Mulher Eterna) em contraste com as implicações práticas desses significados: a imobilidade na experiência de mundo relacionada com a restrição às atribuições domésticas, a dificuldade em sentir-se viva nessas circunstâncias, o aprisionamento identitário da categoria mulher em detrimento do "eu transitório".

A percepção sobre a manutenção da opressão feminina em diferentes épocas e a grande insatisfação interior de Lucy circunscrevem e antecipam a cena violenta de um assassinato que em breve irá testemunhar, e que simbolicamente traduz uma das rupturas observadas no romance de formação tradicional: “o desenvolvimento pessoal e histórico não mais retrata um processo tranquilo e orgânico, mas uma agitação descontínua e violenta"11 (BOES, 2006, p. 237). Essa percepção pressupõe uma reflexão sobre as implicações de uma identidade feminina que toma consciência de si em meio a valores sociais e culturais que a antagonizam. Nesse sentido, o pensamento de Walter Benjamin (2012) sobre a transformação das narrativas na modernidade é bem próximo a Forster. Em O Narrador, Benjamin tece considerações sobre o romance de formação, e argumenta:

Ao integrar o processo da vida social na vida de uma pessoa, ele justifica de modo extremamente frágil as leis que determinam tal processo. A legitimação dessas leis nada tem a ver com sua realidade. No romance de formação, a insuficiência torna-se acontecimento (BENJAMIN, 2012, p. 218).

1 "Development, whether personal or historical, is portrayed not as a gentle organic process, but as a violent and discontinuous upheaval" (BOES, 2006, p. 237). A presente tradução, assim como as demais apontadas pelo original em notas de rodapé ao longo do texto, é de nossa autoria e responsabilidade. 
Autodescoberta e alteridade em um quarto com vista e Maurice, de E. M. Forster José Ailson Lemos de Souza

A insuficiência a que se refere Benjamin, resultante da tentativa de integrar demandas individuais e coletivas na forma romanesca, é um dos elementos mais explorados nos romances em foco.

Durante o passeio, Lucy adquire algumas reproduções: o Nascimento de Vênus, de Botticelli, A tempestade e o Idolino, de Giorgione, gravuras com representações dos afrescos da capela Sistina e Apoxyomenos (imagens de esculturas gregas que retratam atletas). $\mathrm{Na}$ ocasião da compra, ela se lembra dos comentários de Charlotte sobre Vênus que, anteriormente, haviam feito Lucy desistir da aquisição: a exibição da nudez era lamentável. Em posse das reproduções e com o sentimento de tédio, já que nada de impressionante havia acontecido até então na viagem, ela se depara com um violento assassinato. Dois italianos discutiam por dinheiro e um deles é esfaqueado. O homem ferido vira-se para Lucy, "como se tivesse uma mensagem importante para ela" (FORSTER, 2006a, p. 70). Um fio de sangue escorre pela boca do homem e, então, a multidão o cerca. Lucy desmaia e deixa o pacote com as reproduções cair ao chão, misturando-se com o sangue do homem. Tendo em vista a importância dessa cena - o próprio George, em segui$\mathrm{da}$, declara que o testemunho representava um ponto decisivo em suas vidas ("algo mais havia ocorrido com os vivos") -, é importante considerar um pouco mais esse trecho e o que ele sugere sobre a transformação pela qual passa a protagonista.

A crescente insatisfação de Lucy ganha contornos de uma identificação que ultrapassa o binarismo de gênero que orienta seu meio social. Essa identificação aproxima-se do que Laura Mulvey (1989) concebe como "trans-sexual", que seria o conceito de Freud para a masculinidade na mulher. Na leitura que Mulvey (1989) faz de Freud, o anseio expresso por "nada acontece comigo" seria um sentimento tipicamente heroico que revela uma espécie de reconhecimento de uma invulnerabilidade onipotente. A diferença sexual codificada na narrativa opõe a mulher (elemento passivo) ao homem (ação personificada), porém, quando a identificação da mulher se dá pelo significante da ação, teríamos uma "identificação trans-sexual" (MULVEY, 1989, p. 32). É significativo que, após 
Autodescoberta e alteridade em um quarto com vista e Maurice, de E. M. Forster José Ailson Lemos de Souza

experimentar aquela espécie de invulnerabilidade, Lucy presencie um assassinato como uma "representação viva" decorrente da ação masculina. A vertigem diante da imagem talvez indique o choque causado pela percepção das implicações e codificações de gênero.

O testemunho do assassinato na Piazza também destaca as mudanças experimentadas na virada do século com as novas técnicas de reprodução, as quais abririam espaço para mudanças de paradigmas em torno dos gêneros. Walter Benjamin (2012), no ensaio seminal sobre a arte no contexto das novas técnicas de reprodução, aborda algumas transformações que iluminam a discussão levantada no romance de Forster. Benjamin (2012) afirma que a fotografia, e também o cinema, colocou em questão uma série de atributos em torno da arte: gênio, autenticidade, valor eterno. A reprodução, nesse novo contexto, aproxima a obra do indivíduo de um modo impensável em outras épocas e, com isso, valores transmitidos pela tradição (origem, ação do tempo, testemunhos históricos) perdem o peso. A reprodução é um dispositivo destrutivo e catártico para Benjamin (2012), no sentido de demandar outros valores como aqueles tradicionalmente transmitidos. Essa demanda estaria ligada a "convulsões sociais", responsáveis por alterar (metamorfosear) a percepção.

A função social da arte, nesse novo contexto, encontra-se emancipada de paradigmas como aura, "eternidade" (Mulher Eterna), valor de culto, abrindo espaço para outras perceptivas, como o valor de exposição (princípio que torna o aspecto artístico secundário) e a "perfectibilidade": novas imagens podem ser escolhidas, mais adequadas, por exemplo, a representações que desestabilizam os discursos tradicionais sobre a diferença de gênero. Nesse ponto, Benjamin (2012) discute as novas possibilidades trazidas pelas técnicas de montagem e finalização no cinema. Mas podemos pensar numa correspondência entre as ideias de Benjamin (2012) sobre novos paradigmas para as artes que desafiavam a tradição e a necessidade de reformulações de paradigmas sociais para atender às exigências de sujeitos políticos minoritários, como 
Autodescoberta e alteridade em um quarto com vista e Maurice, de E. M. Forster José Ailson Lemos de Souza

as mulheres, cujo acesso à educação, ao trabalho e à independência também colocava em tensão a urgência por mudanças e a força e opressão atrelados à tradição.

O entrelaçamento discursivo da opressão de gênero nas artes e na realidade assomam no texto de Forster com o sangue do homem se misturando às reproduções de Lucy na Piazza. A continuidade entre representação e vida fica evidente. Antes dessa sobreposição ser dramatizada, em referência ao percurso histórico de dominação da mulher, repleto de violência, o texto problematiza as relações de gênero implicadas nas artes e no cotidiano. A resistência da personagem às codificações de gênero aparece assim que ela recobra os sentidos e compreende ter repetido o gesto de "fragilidade feminina", ao desmaiar e ser socorrida por George. Os personagens agem de acordo com as circunstâncias, mas reeditam o discurso que sugere, dentre outras convenções, que cabe ao homem proteger a mulher. A compreensão dessas implicações envergonha Lucy, que tenta fugir do local quando George se afasta para buscar o pacote com as reproduções. O romance manipula a tensão entre representação e experiência vivida de modo a movimentar a narrativa a partir de gestos, afetos e resistências em torno das convenções de gênero.

O anúncio sobre a mudança de paradigmas a partir da identificação trans-sexual de Lucy é feito por George: algo além do assassinato havia acontecido com os vivos. Essa observação, parece-nos, situa o romance de Forster como bildungsroman de modo próximo ao que Mikhail Bakhtin (1986) articula sobre o gênero literário: a apresentação do homem no processo de vir a ser (becoming). Levando em consideração que quem ocupa essa posição no romance é Lucy, pensamos que ela personifica, de forma simbólica e bastante significativa, um momento de transição entre épocas. Segundo Bakhtin, no bildungsroman: "O protagonista não se situa no interior de uma época, mas na fronteira entre duas épocas, no ponto de transição de uma para outra. Essa transição realiza-se nele e através dele"2 (BAKHTIN, 1986 apud BOES, 2006, p.

2"He is no longer within an epoch, but on the border between two epochs, at the transition point from one to the other. This transition is accomplished in him and through him" (BAKHTIN, 1986 apud BOES, 2006, p. 236). 
Autodescoberta e alteridade em um quarto com vista e Maurice, de E. M. Forster José Ailson Lemos de Souza

236). Lucy simboliza um momento de transição, como deveras foi o período eduardiano ${ }^{3}$, que marcaria profundas mudanças sociais e culturais a produzir outras identidades femininas, cujos desejos, independência e poder de ação representam uma verdadeira quebra dos valores vitorianos.

As ocasiões de passeio no romance são propícias para situar Lucy como ponto de observação, problematizando sua perspectiva como "princípio ativo", de movimento no interior da narrativa. Durante o passeio do grupo de turistas pelos arredores de Florença, a perspectiva de Lucy cede lugar para que o narrador a apresente numa cena de grande apelo erótico:

De seus pés o terreno precipitava-se abruptamente para a vista, e violetas corriam em regatos, correntes e cataratas, irrigando as encostas de azul, engolfando os caules das árvores, desaguando-se em piscinas nas baixadas, cobrindo o relvado com manchas de espuma cerúlea. Mas em nenhum outro lugar elas se amontoavam em tamanha profusão; aquele terraço era a nascente, a fonte iniciática de onde a beleza irrompia para banhar a terra.

De pé à sua beira, como um nadador que se prepara para o salto, estava o bom homem. Mas ele não era o bom homem que ela esperava, e estava sozinho (FORSTER, 2006a, p. 103).

A profusão de violetas, aludindo à vitalidade, beleza e amor, em meio a regatos, correntes, cataratas e piscinas que sugerem fertilidade compõem um cenário propício para a "beleza banhar a terra", criando um quadro de sensualidade latente. Além disso, George figura como um nadador, o que sugere uma imagem de apelo erótico, associando-o com nudez, total ou parcial. A força com a qual o personagem funciona na narrativa como estímulo erótico é tamanha que sua qualidade de "objeto" de apreciação se repete continuamente ao longo do romance, como quando

3 Período que se refere ao breve reinado do Rei Edward (1901-1910), marcado por rápidas transformações no início do século passado. 
Autodescoberta e alteridade em um quarto com vista e Maurice, de E. M. Forster José Ailson Lemos de Souza

Lucy tenta explicar o que aconteceu para a prima. Ela reconhece ter "parcela de culpa", pois contemplou pensamentos tolos, "e, por um momento, ele se me afigurou como uma figura num livro" (FORSTER, 2006a, p. 108).

Lucy, entretanto, resiste a ser posicionada como objeto de observação por vários personagens (além de Cecil, ela é "alvo" de Beebe e Eleanor Lavish). Quando se torna noiva de Cecil, o conflito se instaura com as iniciativas dele em "imobilizá-la", enfatizando o poder que o casamento confere na consolidação desse desejo com analogias entre Lucy e pinturas italianas. Quando ele faz o pedido de casamento e é, num primeiro momento, aceito, forma-se uma cena confusa, por envolver o sentimento misto de comemoração e repulsa por parte da família de Lucy. Na ocasião, Cecil relembra o dia em que a encontrou em Roma. Ele havia então identificado nela o efeito maravilhoso que a Itália havia provocado: "deu-lhe luz". E, ainda melhor, "deu-lhe sombras". Para ele, Lucy é como uma muIher de Leonardo da Vinci, amada não por atributos próprios, mas pela atmosfera de mistério: "nenhuma mulher de Leonardo teria algo tão vulgar a oferecer quanto uma história" (FORSTER, 2006a, p. 129). Essa expectativa opõe-se ao que Lucy, no início da narrativa, aspira: ter histórias, experiências e feitos são demandas que ela descobre em meio às obras de arte florentinas.

Depois de auxiliar Charlotte na discussão sobre a troca de quartos com os Emersons, Beebe pondera sobre a transformação que percebe em Lucy quando ela está ao piano. A entrega à execução de notas a absorve de modo a não se dar conta do que ocorre ao redor: o senhor Emerson corre à procura do filho. Charlotte busca Eleanor. E esta, logo em seguida, aparece à procura da cigarreira. Beebe observa essa movimentação sentado, como que invisível, junto a janela, lembrando a forte impressão que teve quando ouviu Lucy tocar o Opus 111 de Beethoven, em Tunbridge Wells. $O$ reverendo demonstra grande sensibilidade e conhecimento sobre música clássica e, comicamente, admira-se com o fato de Lucy, com o talento que tem, interessar-se em ouvir seus sermões na paróquia. Ele relembra o comentário que fez sobre Lucy após a 
Autodescoberta e alteridade em um quarto com vista e Maurice, de E. M. Forster José Ailson Lemos de Souza

apresentação em Tunbridge Wells: "Se a senhorita Honeychurch algum dia chegar a viver como toca, será muito excitante: para nós e para ela" (FORSTER, 2006a, p. 56).

A leitura que Beebe faz sobre Lucy é a de uma jovem com grande potencial para quebrar paradigmas. Ela o surpreendeu pela composição escolhida, pela execução intensa e apaixonada, e pela entrega aos sentidos. Infere-se que a potencialidade de Lucy em subverter estereótipos e convenções é o que a torna interessante como heroína, tanto para Beebe quanto para nós leitores.

\section{Alteridade de classe em Maurice}

Maurice (2006) enfatiza um entrelaçamento entre hierarquias de classe e homofobia, de modo que um reconhecimento da homossexualidade presume o enfrentamento da divisão social entre privilegiados e classe trabalhadora. As cenas de reconhecimento podem ser divididas entre uma que falha, no caso da relação entre o protagonista e Clive Durham, que resiste a tornar-se "outro" na sociedade conservadora que habita e, desse modo, perder os privilégios assegurados por aquela estrutura social. Maurice, por outro lado, protagoniza um reconhecimento que desafia as normas vigentes, que puniam a homossexualidade. A saída encontrada para poder viver de acordo com suas demandas pessoais acontece através de uma alteridade social: a relação amorosa que firma com Alec Scudder, o guarda-caças da família de Clive.

A alteridade, o encontro com a diferença, o reconhecimento de si (no caso de Maurice, de seus privilégios e limitações) na sociedade heteronormativa e patriarcal tem papel fundamental no romance. Esse elemento encaminha a narrativa para dois quadros distintos. O primeiro deles apresenta os conflitos entre Maurice e Clive para vivenciarem uma relação amorosa. O conflito da sexualidade com as normas sociais conduz Clive a resguardar-se no casamento. O segundo quadro se forma a partir do encontro de Maurice com Alec, seu outro social. Essa alteridade viabiliza um 
Autodescoberta e alteridade em um quarto com vista e Maurice, de E. M. Forster José Ailson Lemos de Souza

quadro positivo, de emancipação e realização individual na narrativa, mas coloca em perspectiva mais investimento simbólico do que palpável, dada as condições legais e culturais em que ocorre a história. Essa perspectiva, contudo, problematiza contextos de opressão e formas de agir (saídas possíveis) que contribuem para revestir o romance de uma qualidade: de elaborar perspectivas futuras mais igualitárias e justas.

Judith Butler (2015) destaca o reconhecimento como evento que desorienta a noção de identidade e que, a partir do desejo, pode desencadear o questionamento de si:

Em certo sentido, submeto-me a uma norma de reconhecimento quando te ofereço reconhecimento, ou seja, o "eu" não oferece reconhecimento por conta própria. Na verdade, parece que o "eu" está sujeito à norma no momento em que faz a oferta, de modo que se torna instrumento da ação daquela norma. Assim, o "eu" parece invariavelmente usado pela norma na medida em que tenta usá-la. Embora eu pense que estive tendo uma relação com o "tu", descubro que estou presa em uma luta com as normas (BUTLER, 2015, p. 39).

$\mathrm{O}$ ato de reconhecer estaria condicionado às normas disponíveis. A luta com as normas parece inviabilizar uma pretensão ao livre-arbítrio, complicando a noção de sujeito da ação. Porém, esse conflito surge do desejo de reconhecer o outro, o que permite um espaço de questionamento sobre o lugar e a delimitação das identidades.

O tipo de alteridade implícita na noção de reconhecimento em Butler (2015), que atenta para a capacidade das subjetividades de se desorientar e questionar, além de afirmar "nossa cegueira comum", ou seja, nossa incapacidade de nos conhecermos por completo, tem como desdobramento a impossibilidade de constituirmos identidades fixas e imutáveis. O que é interessante nessa perspectiva é a possibilidade de produzirmos novos sujeitos polí- 
Autodescoberta e alteridade em um quarto com vista e Maurice, de E. M. Forster José Ailson Lemos de Souza

ticos. Tendo em mente a importância da alteridade social no romance, passamos à análise desse elemento.

Hospedado na casa de Clive, Maurice se encontra com Alec Scudder, com quem ultrapassa o viés platônico do antigo relacionamento e pode finalmente experimentar uma relação completa. Com Maurice e Alec, Forster reprisa um de seus temas mais recorrentes: o tabu das diferenças de classe. Em Where Angels Fear to Tread (1905/2011), Lilia Herriton e o italiano Gino enfrentam conflitos devido às diferenças culturais, etária e, principalmente, de classe social. Exceto pela questão da nacionalidade, o mesmo ocorre em Um Quarto com Vista (1908/2006), entre Lucy Honeychurch e George Emerson, e entre Helen Schlegel e Leonard Bast, em Howards End (1910/2000). Segundo Adam Kirsch (2015), esse tema está inserido numa discussão mais ampla presente em Forster, a favor da liberdade sexual e do autoconhecimento frente às convenções morais e sociais de seu tempo. Nesse sentido, Kirsch $(2015$, p. 2) compreende que o lema "Ligue, simplesmente" presente em Howards End e comumente retomado pela crítica como uma espécie de chamado à superação de barreiras sociais, culturais e de gênero que segregam os indivíduos, frisa "a dificuldade de conectar nossa personalidade habitual e convencional com nossos desejos sexuais transgressivos" ${ }^{\prime \prime}$. Segundo o autor, os romances de Forster enfatizam a importância de superar certa hipocrisia sexual para assim atentar às demandas da atração, e isso seria mais uma questão de liberdade de consciência do que de apetite sexual.

Uma ligação com Alec representa um tabu duplo, pois, além da homossexualidade, viola as convenções de segregação social acentuadas naquele contexto. Essa diferença também será obstáculo para a relação dos amantes. Alec demonstra não conformidade com as expectativas em relação à posição social que ocupa. Logo que aparece na narrativa, ele recusa uma gorjeta oferecida por Maurice. Maurice e Archie London, outro amigo de Clive, conversavam sobre a crescente insolência dos criados, "gente com educação pela metade" (FORSTER, 2006b, p. 180). A conversa é en-

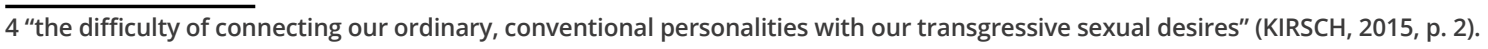


Autodescoberta e alteridade em um quarto com vista e Maurice, de E. M. Forster José Ailson Lemos de Souza

fadonha para Maurice, mas demarca bem o território da diferença de classes sobre a qual se desenvolverá a relação entre os personagens. Além disso, a referência à educação insuficiente como forma de explicar a atitude de Alec sugere também que, do ponto de vista dos personagens privilegiados, é através da "educação" que se normalizam relações de exploração.

Uma interessante articulação de imagens divide o encontro amoroso de Maurice com Clive e, posteriormente, com Alec. Clive, nos tempos da faculdade, desentende-se com Maurice e os dois se afastam temporariamente. No embate com o sentimento de culpa e pecado, Clive é visitado por Maurice, que entra no quarto pela janela após ter sido "chamado". Trata-se de um sonho romântico. Anos depois, hospedado na casa do antigo amante, Maurice, desperto e inquieto com a ineficiência das consultas e hipnoses que visavam "tratar" e alterar seu objeto de desejo, também faz um chamado. Ele não nomeia quem, apenas verbaliza para o vazio o desejo de um encontro. Alec, como se também fosse uma projeção da fantasia, entra no quarto e os dois passam a noite juntos. A partir desse encontro, da materialidade da relação sexual, Maurice liberta-se do limbo em que se encontrava, entre o desejo e a negação.

Após a primeira noite de sexo, entretanto, surgem diversos problemas relacionados à diferença de classe. A vontade de agradar o amante é colocada nesses termos: O que dar a um "homem de seu nível social?" (FORSTER, 2006b, p. 202). Simcox, um dos criados da residência, entra no quarto (Maurice já está sozinho), abre as cortinas, organiza as roupas de Maurice e sua agenda de atividades. O quadro, aparentemente harmônico, é altamente sugestivo e contrastante. A abertura para a realização sexual de Maurice coloca em questão lados opostos da estratificação social: os privilegiados, assim como ele, e a classe trabalhadora. Uma conciliação de interesses possíveis fica cada vez mais distante diante dos fatos materiais.

Não demora até Maurice passar a temer ser chantageado por Alec, com base no histórico de golpes dessa natureza na época, a 
Autodescoberta e alteridade em um quarto com vista e Maurice, de E. M. Forster José Ailson Lemos de Souza

partir da posse de bilhetes, cartas ou testemunhas que comprovassem o sexo entre homens. Alec, quando não recebe mais respostas para a correspondência que inicia, teme ter sido apenas um objeto sexual. E sua reaproximação de Maurice se dá apenas quando o chantageia.

Apesar dos percalços, o recurso a um discurso sentimental é utilizado por Forster para tratar da realização sexual entre os personagens. Entre Alec e Maurice, o recurso ganha contornos ainda mais intensos, como transparece no seguinte trecho, durante um jogo de críquete na propriedade de Clive:

Alec não recebera treinamento específico, mas tinha jeito para o críquete, e o jogo tornou a ficar sério. Maurice também jogou bem. Sua mente havia acelerado e sentiu como se estivessem jogando contra o mundo todo: não eram apenas o senhor Borenius e os jogadores, mas também as senhoras no abrigo e toda a Inglaterra, todos cerravam forças em torno dos wickets. Maurice e Alec jogavam um pelo outro, e em prol de seu frágil relacionamento - se um caísse o outro seria derrubado também. Não pretendiam causar nenhum mal ao mundo, mas, se ele os assaltasse, haveriam de castigá-lo, precisavam estar a postos e então atacar com toda a força, precisavam mostrar que, quando dois se juntam, as maiorias não triunfam (FORSTER, 2006b, p. 205, grifo do autor).

No entanto, a tensão decorrente da diferença de classes permeia o enredo em diferentes níveis. Antes do jogo de críquete, Simcox demonstra grande adequação à função que cumpre (certamente foi "bem educado") ao afirmar que "as coisas sempre se dão melhor quando um cavalheiro as comanda" (FOSTER, 2006b, p. 204), em resposta à sugestão de Maurice para ser substituído por Alec no comando do jogo. Para Simcox, até mesmo num simples jogo amador, o "apropriado" era repetir a hierarquia de classe.

Além disso, a efusão romântica destacada no trecho acima rapidamente se dissolve e cede espaço para a ansiedade gerada 
Autodescoberta e alteridade em um quarto com vista e Maurice, de E. M. Forster José Ailson Lemos de Souza

pela diferença. Maurice, quando se retira do campo, passa pelos empregados e nota que a maioria se levanta e aplaude seu desempenho, menos Alec, o que o deixa alarmado. A superposição entre diferença de classe e uma possível conciliação como chave para a emancipação sexual salientam para o protagonista a relação inextrincável entre sexo, gênero e classe social na estrutura de opressão que, por um lado, privilegia-o e, por outro, proscreve-o. É por meio da alteridade social que o protagonista percebe "que as coisas não funcionam do mesmo modo para todos" (FORSTER, 2006b, p. 207).

Medo, ansiedade, vergonha e arrependimento fazem com que Maurice interprete cartas amorosas como armadilhas e ameaças. $O$ fato de ser um cavalheiro, ter frequentado escolas de elite e, ao final, ter se permitido envolver com Alec o perturba. O pensamento sobre quem ele é, na hierarquia social, em contraste com Alec, levam-no a concluir que precisa "ser fiel à sua classe" (FORSTER, 2006b, p. 218). Os afetos acionados pela alteridade de classe não expressam apenas um processo de autoavaliação, como parece sugerir o texto, mas a avaliação de si no interior de estruturas sociais.

Alec não aceita o distanciamento sem um último encontro. As mensagens se acumulam até que ele recorre à ameaça. No texto truncado do bilhete enviado em que alterna informações sobre Penge, a propriedade de Clive, a mágoa com a falta de reciprocidade por parte de Maurice, autoafirmações sobre sua família, origem e ameaça de provocar escândalo - caso Maurice não o encontre - se alternam de modo a enfatizar um baixo grau de instrução escolar. Ele também revela que sabe (os criados sabem) do caso entre Maurice e Clive. A mensagem de Alec tem o efeito de fazer Maurice sentir-se abjeto ("podia sentir seu fedor"), mas, por outro lado, ele também experimenta alívio com o fato de terceiros conhecerem sua história com Clive. A própria carta, que num primeiro momento o desagradava com "palavras imbecis e imundas", ao final, poderia ter sido escrita por ele próprio (FORSTER, 2006b, p. 220). O orgulho ferido de Alec, seu interesse em seduzir, junto ao conhecimento da experiência amorosa passada de Maurice, 
Autodescoberta e alteridade em um quarto com vista e Maurice, de E. M. Forster José Ailson Lemos de Souza

são elementos que deslocam a ameaça e colocam o protagonista numa cena de reconhecimento, evento diretamente relacionado com o despertar da empatia.

O tenso reencontro entre Alec e Maurice ocorre no Museu Britânico. O local era público e ao mesmo tempo discreto, onde dificilmente encontrariam conhecidos. Porém, o senhor Ducie, antigo professor de Maurice, surge no momento em que Alec, meio atrapalhado, ensaiava chantagear Maurice. Ducie reconhece a voz de Maurice, mas não consegue se lembrar de seu nome. Maurice então se protege, apresenta-se como Scudder. O mal-entendido tem o efeito de apaziguar os ânimos entre os amantes que, enfim, entendem-se. O professor, que no passado se enganou quanto ao curso da vida sexual de Maurice, é quem oferece o significado da cena no museu. Para ele, o Museu Britânico "não era apenas uma coleção de obras raras, mas um lugar em torno do qual se podia imaginar... eh... os menos afortunados, é bem verdade... Um lugar estimulante... Suscitava questões até mesmo na mente dos rapazes" (FORSTER, 2006b, p. 228). A ligação entre os dois pode ser compreendida nesses termos, um desfecho disponível mais como conjectura imaginada do que real.

Anteriormente, o médico com quem Maurice se consultava havia recomendado que ele se mudasse para França ou Itália, locais em que poderia viver de acordo com sua sexualidade. Afinal, nesses países, a homossexualidade não era mais considerada crime. Portanto, a decisão de Maurice e Alec de se unirem e permanecerem na Inglaterra encerra um final feliz, mas cuja perspectiva de continuidade desafia para a luta e para o desconhecido. A decisão de se unir com Alec retira Maurice do invólucro de proteção que sua classe oferece. Essa reflexão é literal e emana do próprio personagem. Ao pensar sobre seus clientes de "classe média média", seus pares têm em comum:

O desejo de proteção. Proteção em todos os lugares e momentos, até que a existência da terra e do céu fosse esquecida, proteção contra a pobreza, a doença, a violência e a falta de edu- 
Autodescoberta e alteridade em um quarto com vista e Maurice, de E. M. Forster

cação; e consequentemente, contra a alegria; [...] nenhum deles conhecera a felicidade verdadeira. A sociedade Ihes provera por completo. Nunca tiveram de lutar (FORSTER, 2006b, p. 222).

Diante de normas e poderes institucionais que o excluem, Maurice compreende que sua posição, a partir de sua ação, demanda lutar. Não há ainda estratégias para esse enfrentamento. Isso fica claro quando ele conversa com Alec sobre a luta que os aguarda no futuro em diante, apenas uma consciência da atitude necessária.

Ao superar as diferenças e permanecer juntos, eles deixam para trás pequenos confortos, o sentimento de proteção simulado pela vida em sociedade, bem como os condicionantes castradores de suas sexualidades. Alec e Maurice desertam da cidade para uma zona rural e não são mais vistos. O exílio resulta de um processo de transformação profunda para o protagonista e da alternativa de vida plena então disponível, no sentido de explorar sua sexualidade. $O$ exílio social como alternativa, entretanto, repercute também a condição de perda imposta a dissidentes, refugiados e imigrantes que procuram escapar de perseguições e ameaças, bem como de um final trágico, como tem sido, infelizmente, o destino de diversos grupos vulneráveis à instrumentalização do ódio.

Edward Said (2000) problematiza o exílio, que algumas vezes surge na literatura e na história atrelado a circunstâncias heroicas e vitoriosas, como experiência de fratura e profunda tristeza. O autor cita George Steiner, que, talvez com conhecimento de causa, acerta na identificação de um gênero característico da literatura ocidental, a "literatura extraterritorial", que seria aquela "produzida por exilados e para exilados" (SAID, 2000, p. 174). Segundo Steiner, o paradoxal híbrido de civilização e barbárie, que caracterizou o século passado, teve o efeito de "criar" um coletivo de artistas desabrigados, "andarilhos entre línguas", a produzir, a partir desse lugar afastado, nostálgico e imprevisível, imagens de perda e mutilação que se confundem com o próprio século. Nesse ponto, Mauri- 
Autodescoberta e alteridade em um quarto com vista e Maurice, de E. M. Forster José Ailson Lemos de Souza

ce situa a dissenção sexual na "literatura extraterritorial", fundindo a imagem edênica (nostálgica) do refúgio encontrado com sobrevida, mas também com a ruptura dolorosa de laços imposta pelo poder que alguns indivíduos têm sobre a vida de outros. A época em que vivemos, lamentavelmente, presencia o adensamento de tensões que caracterizaram os horrores do século anterior.

Uma segunda cena de reconhecimento ocorre quando Maurice informa Clive sobre o caso com Alec, sobre o que havia acontecido entre os dois, até então, e sobre a decisão dos amantes de levarem a relação adiante. Para Clive, aquele tipo de intimidade com alguém "socialmente inferior" era impensável. Além disso, a possibilidade de realização sexual que Maurice descrevia assomava como um "monstro" que Clive queria golpear e sair correndo. O impulso violento é contido, pois era um homem de Cambridge, "dois pilares da sociedade" (FORSTER, 2006b, p. 247). Forçar Clive a ver que, pelo menos, o desejo e a coragem por liberdade sexual movem outros indivíduos a buscar alternativas funciona para Maurice como o "fechamento de um livro", em que a fala, o verbalizar de uma forma de amor e de vida, irrompe como insurreição: “Eu teria sido seu até o fim se quisesse ficar comigo, mas agora sou de outra pessoa (não posso ficar me lamuriando para sempre) e ele é meu de um modo que o ofende, mas porque não para de ficar sendo ofendido e se ocupa de sua própria felicidade?" (FORSTER, 2006b, p. 249). A pergunta espantada de Clive, "quem o ensinou a falar desse modo"?, além de expressar o espanto do personagem, pode ser entendida como questionamento das normas diante de um discurso que até então não havia sido articulado na literatura inglesa por estar fora do aceitável.

O termo homossexualidade aparece apenas no texto da nota final. O romance de Forster pode ser visto como um percurso de expressões variadas para o desejo homoerótico. No momento da escrita do livro, a discussão sobre esse desejo experimentava um embate decisivo no estabelecimento da homossexualidade como uma forma nova e proscrita de vida. Edward Carpenter, uma figura importante na disputa teórico-jurídica sobre esse desejo na In- 
Autodescoberta e alteridade em um quarto com vista e Maurice, de E. M. Forster José Ailson Lemos de Souza

glaterra, como Forster lembra, lutava pelo reconhecimento desse desejo como emoção favorável a reintegrar os indivíduos numa ordem mais harmônica e generosa. O romancista enfatiza que, mesmo menos otimista que Carpenter, chegou a pensar que o reconhecimento para o que hoje designamos como homossexualidade seria uma questão de compreensão:

Não havíamos percebido que aquilo que o público realmente abomina na homossexualidade não é a coisa em si, mas o fato de ser obrigado a pensar nela. Se ela pudesse ser inserida em nosso meio de forma despercebida ou então fosse legalizada da noite para o dia num decreto escrito em letras miúdas, haveria poucos protestos (FORSTER, 2006b, p. 257).

Forster chega ao ponto nevrálgico da problemática do reconhecimento em torno da homossexualidade, que direcionou tanto a trajetória de Maurice, sua recepção, os ganhos, avanços posteriores em prol de direitos igualitários em algumas sociedades e os retrocessos do presente: a alteridade falha porque o reconhecimento implica um "pensar" em outra forma de vida. O não reconhecimento, portanto, é uma negação não da homossexualidade em si, mas de sua representação, de sua inserção no imaginário mais amplo de uma coletividade. Esse banimento reforça o jogo ideológico manipulado através da representação, questão levantada tanto no interior dos romances de Forster quanto nas discussões em torno das obras.

\section{Considerações finais}

Um Quarto com Vista explora, em narrativa de autodescoberta, uma tomada de consciência feminina sobre as forças sociais e valores culturais que, codificados em diversas manifestações da representação, oferecem uma identidade de gênero insuficiente, e é exatamente essa insuficiência que movimenta a narrativa. 
Autodescoberta e alteridade em um quarto com vista e Maurice, de E. M. Forster José Ailson Lemos de Souza

Esse processo, elaborado no interior de um romance de formação que tematiza mudanças e transformações históricas corporificadas numa protagonista, apresenta uma imagem do feminino que emerge, de maneira subversiva, com uma percepção de si no interior de normas e códigos sociais que a antagonizam. O enfrentamento de tais restrições ocorre a partir da realização sexual com George, ao invés de um casamento de aparências com Cecil.

Com Kirsch (2015), compreendemos que enfrentar a hipocrisia sexual e ter a coragem de afirmar as demandas do desejo genuíno é um princípio que está além do mero prazer sexual, representa um posicionamento político numa sociedade altamente conservadora, como era a Inglaterra eduardiana. Essa ruptura com as convenções ocorre após um percurso no qual Lucy depara-se com a lógica de dominação masculina, simbolizada no vínculo entre representação artística e experiência vivida.

Destacamos em Maurice diferentes cenas de reconhecimento da experiência homossexual. O reconhecimento que acompanha a realização pessoal do protagonista sugere a intermediação com uma alteridade de classe. Naquele contexto, fica claro que a homossexualidade deveria permanecer invisível para a sociedade, caso contrário, a manutenção do lugar social e a própria liberdade dos indivíduos estariam em risco. Se com seu par social, Clive, a cena de reconhecimento falha, com Alec Scudder abre-se uma possibilidade para Maurice experimentar o reconhecimento através da alteridade social. Em nota ao final do romance póstumo, Forster observa que o reconhecimento é um aspecto central da experiência homossexual, afinal, a sociedade abomina não a homossexualidade em si, mas o fato de ser obrigado a pensar nela.

Os romances sugerem uma compreensão sobre o entrelaçamento de diferentes formas de opressão presentes na diferença de gênero e classe social e que não se pode combater uma dessas categorias sem questioná-las em conjunto. Através de Lucy e Maurice, os romances problematizam os discursos que impõem contornos e limites para identidades descritas por contornos de gênero e classe social. É a partir da conscientização sobre esses 
Autodescoberta e alteridade em um quarto com vista e Maurice, de E. M. Forster José Ailson Lemos de Souza

limites que os protagonistas de Forster agem para inserir os próprios termos em suas trajetórias.

\section{Referências}

BENJAMIN, W. Magia e técnica, arte e política: ensaios sobre literatura e história da cultura. Tradução de Sérgio Paulo Rouanet. São Paulo: Brasiliense, 2012.

BOES, T. Modernist Studies and the Bildungsroman: A Historical Survey of Critical Trends. Literature Compass, New Jersey, v. 3, n. 2, p. 230243, 2006.

BOOTH, H. J. Maurice. In: BRADSHAW, D. (Ed.). The Cambridge

Companion to E. M. Forster. Cambridge: Cambridge University Press, 2007. p. 173-187.

BUTLER, J. Relatar a si mesmo: crítica da violência ética. Trad. Rogério Bettoni. Belo Horizonte: Autêntica, 2015.

BUTLER, J. Problemas de gênero: feminismo e subversão da identidade. Tradução de Renato Aguiar. Rio de Janeiro: Civilização Brasileira, 2017.

FORSTER, E. M. Where Angels Fear to Tread. New York: Dover, 2011

FORSTER, E. M. Howards End. London: Penguin, 2000.

FORSTER, E. M. Um Quarto com Vista. Tradução de Marcelo Pen. Rio de Janeiro: Globo, 2006a.

FORSTER, E. M. Maurice. Tradução de Marcelo Pen. Rio de Janeiro: Globo, 2006b.

HERZ, J. A Room with a View. In: BRADSHAW, D. The Cambridge Companion to E. M. Forster. Cambridge: Cambridge University Press, 2007. p. 138-150.

KIRSCH, A. Liberation and Liberalism: E. M. Forster. Rocket and Lightship: Essays on Literature and Ideas. New York: W. W. Norton, 2015. (ebook). 
Autodescoberta e alteridade em um quarto com vista e Maurice, de E. M. Forster José Ailson Lemos de Souza

MEDALIE, D. E. M. Forster's Modernism. New York: Palgrave Macmillan, 2002.

MULVEY, L. Afterthoughts on 'Visual Pleasure and Narrative Cinema' inspired by King Vidor's Duel in the Sun (1946). In: MULVEY, L. Visual and Other Pleasures. Bloomington: Indiana University Press, 1989.

SAID, E. Reflections on Exile and Other Essays. Cambridge/

Massachusetts: Harvard University Press, 2000. 